\title{
MANAGEMENT SYSTEM OF THE YOUTH INFORMATION AND COUNSELING CENTER IN KUPANG
}

\author{
Vience Adoe, Sabina Gero, J.F Bale-Therik \\ Masters Program in Public Health, Nusa Cendana University
}

\begin{abstract}
Background: Youth Information and Counseling Center (PIK) in Kota Kupang has been established since 2009. In its development, only $31 \%$ of the total PIK Teenagers enrolled in the KBKS Office of Kupang City were identified as active. Most are still at the "growing" stage. The purpose of this study was to evaluate the management system of the Youth Information and Counseling Center in Kupang.

Subjects and Method: This was a mixed qualitative-quantitative study. The study was conducted at Youth Information and Counseling Center in Kupang. A sample of 6 informants from PIK were selected for this study, consisting of 6 PIK teenagers and head of subdivision of adolescent reproductive health. Qualitative data were collected by in-depth interview and observation. The data collected included availability of human resource managers, infrastructure support, funding support, management process, and teenage user coverage. Quantitative data were collected by questionnaires from 340 respondents. The dependent variables for the quantitative study were knowledge and attitude towards adolescent reproductive health. Qualitative analysis was performed by descriptive analysis. Evaluation of managemen system employed context, input, process, and product (CIPP) framework.

Results: PIK was lacking in input, i.e. infrastructure and equipment. Management process was also lacking. Especially there were no working standard, job description, and monitoring by related agencies. The output (product) side of PIK was low. PIK only covered $42 \%$ of total number of adolescents in Kupang. Quantitative study showed low knowledge and low in positive attitude towards adolescent reproductive health. Nevertheless, adolescents who were active in PIK had better knowledge in reproductive health than "growing" adolescents or other junior high school students.

Conclusion: Youth information and counceling center in Kupang did not well perform. There is a need to provide reproduction health education for adolescents since earliest age.
\end{abstract}

Keywords: youth, information and counseling center, reproductive health, management system

Correspondency: Vience Adoe. Masters Program in Public Health, Nusa Cendana University. Kupang. Email : vmathelda@gmail.com.

Mobile : +628123796215 